\title{
Putting Waste Metals to Work
}

\author{
Methods and Machines That Make It Profitable for Every Plant to Handle Its Own Junk
}

By Robert G. Skerrett

THE salvaging of our metallurgical Terelicts has become a business of imposing proportions, and the more we persist in this form of conservation the better able shall we be to hold our own in the near future in that keen industria competition which is bound to tax productive cunning to the utmost.

The old bit of lead pipe, the odds and ends of cast-off iron, the hattered door knob, the leaky faucet, the tinsmith's waste, the copper kettle that has served its day, and thousands of other articles of allied sorts have long been classed in the popular mind as junk. To the man in the street they have fulfilled their primary purpose and are fit only for the scrap pile. It is mell, hortever, that there are others among us who do not look so indifferently upon these waste materials. In the languge of our Government excexperts such scrap is today dignified as "secondary metals"; and their value in the course of a single year reac
of tens of millions of dollars.

The war we waged upon waste during the recent period of strife brought home to us how spendthrift mee mere ordinarily and practices were then instituted which can be of incalculable good if we persist in them nationally henceforth. From now on the aim of our factories and mills must be to realize quantity output with stricter regard to the costs involved. The problem is not going to be one of prompt-

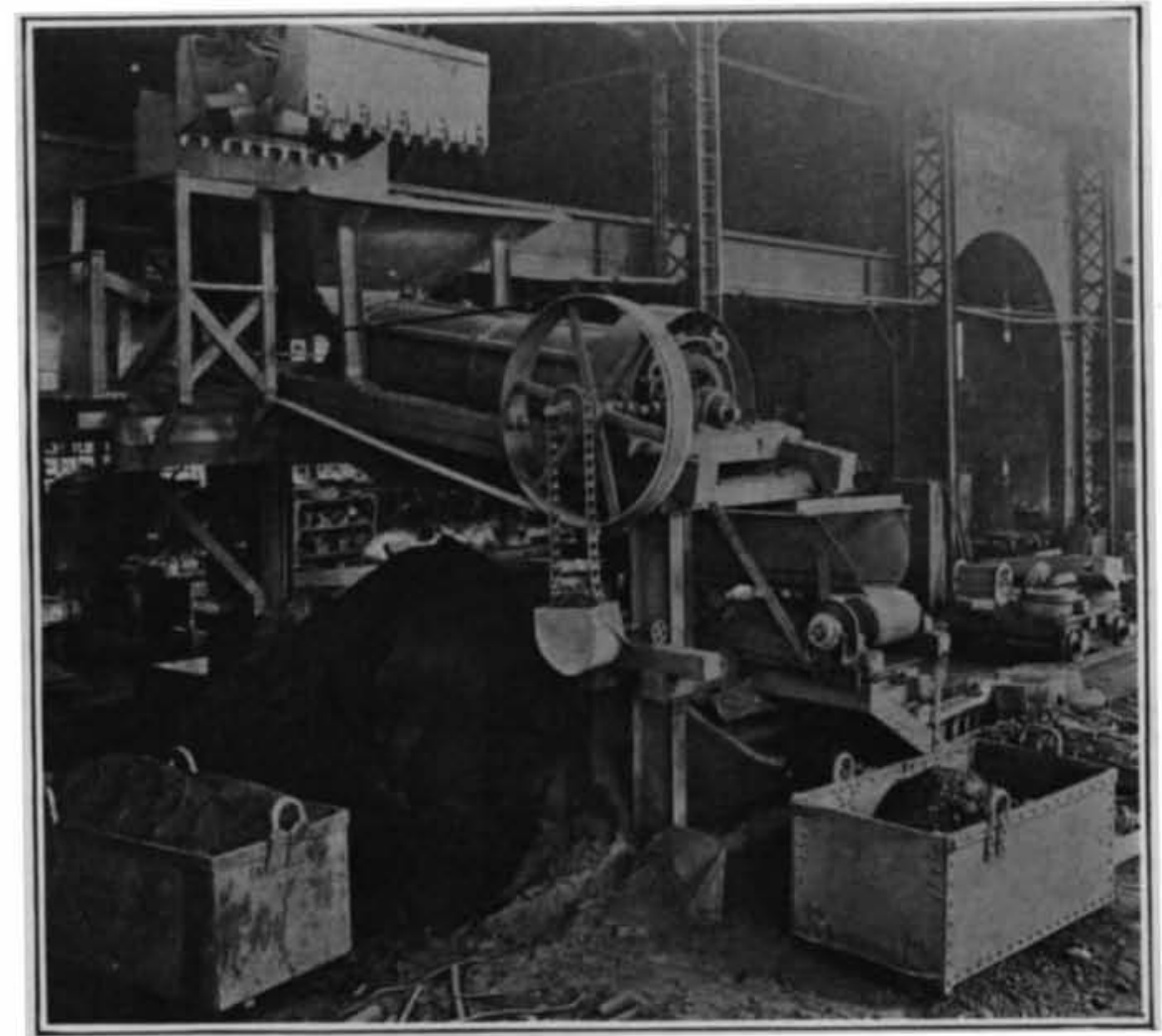

A pulley type of magnetic separator treating foundry waste

furnish the largest share of secondary gold, while silverware and photographic waste vield us most of our secondary silver. According to the Government authorities, the gold or silver contained in old jerrelry, dental waste, silver tableware. ornaments, and other articles remelted two vears hack was in excess of $\$ 27,592$, 060. Mints and refineries reported the recovery of $6,463,002$ fine ounces of silver and $\$ 19.35+, 398$ in gold from refuse or discarded material.

In the course of a twelvemonth one small refinery reclaimed 30,000 ounces of silver from the waste of some moving picture lahoratories. 'Those familiar with the business are aware that a considerable part of well-nigh every new film is spoiled or cut ont before the reel is displayed, and. besides, old films are scrapped All films contain silver in thetr scrapped. All fims contain coatings, and so films are originally developed. It pays to adopt measures to salvage this precious metal.

As many of us know, the lead-in wires of electric light bulbs are commonly made of platinum because the coefficient of expansion of that metal is so low that it will stand wide variations of temperature without tending to crack the enveloping glass. In the past little was done to recover the imbedded filaments in cast-off globes; but an example was set in the direction of conservation during the war a less than $\$ 100,000,000$. This seeming rastage is not hard to understand when we recall how extensively iron and steel figures in the equipment of the rolling stock and the roadbeds of these great and far-reaching common carriers. So much for the baser metals; and now for some of those of the rarer short that are made fit again for service.

The secondary platinum, iridium, and palladium recovered from domestic sources in 1919 was worth $\$ 8,053,26 \overline{5}$, and was more than the value of the platinum and allied metals which we imported for consumption during the same twelvemonth. It may never have occurred to you that when you parted with a filled

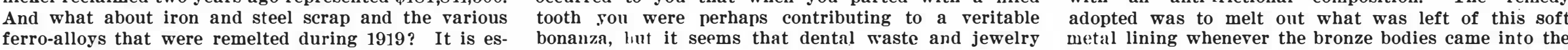

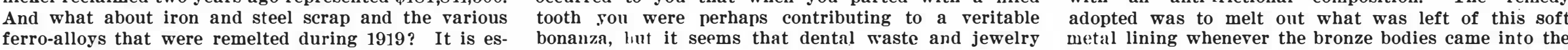
the house of correction of a large Western city. A
testing plant was created for the examination of discarded light bulbs found in the municipal waste. Not only was a sufficient number of good lights thus discovered to meet the needs of the entire institution, but cer than $\$ 9,000$ was reclaimed from the "dead" lamps.

Not long ago the repair-shop foundry of one of our big trunk lines deroted half of its time to the manufacture of new bearings for its rolling stock, but by improved practices this work was reduced nearly 40 per cent. The bearings proper are of bronze and lined with an anti-frictional composition. The remedy

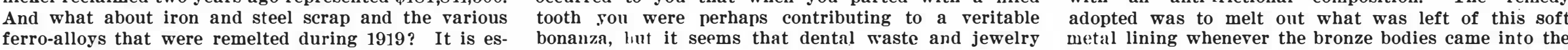

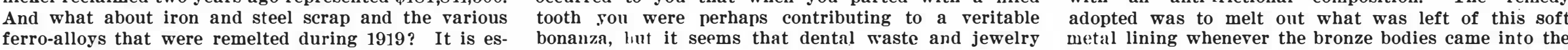
timated that this particular group of timated that this particular group of secondary metals bulked substantiall $8,000,000$ tons and that they ranged in value from seven dollars to several hundred dollars a ton. This happened in a year when our railways were yielding only about 60 per cent of their

Ordinarily, the average yearly discard of iron and steel by our land lines totals about $8,000,000$ tons, and at a conservative figure this material

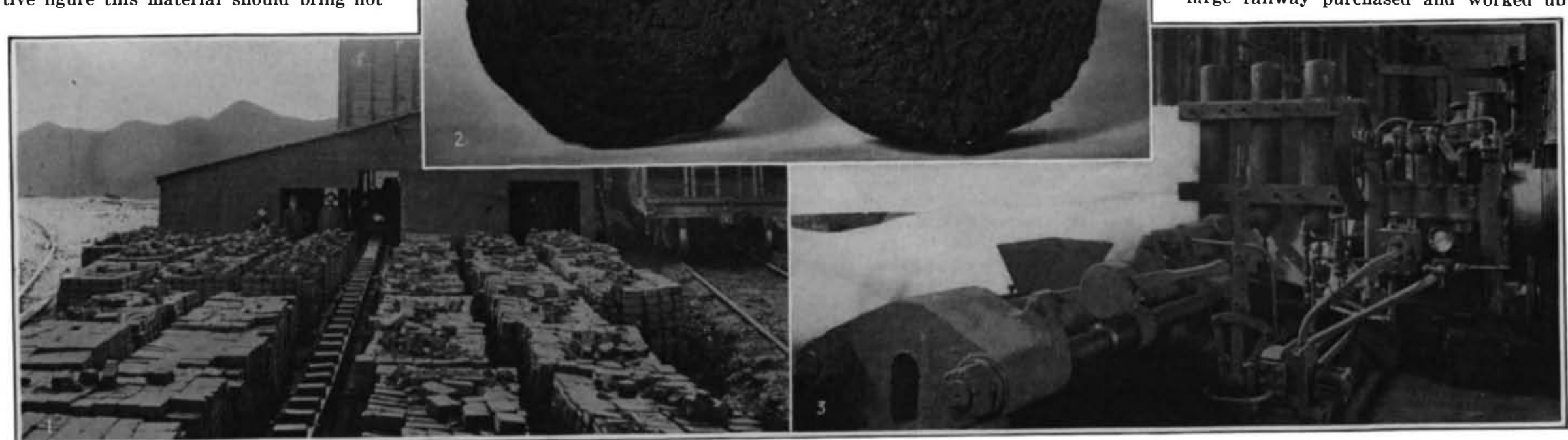

Left: Briquets of flue-dust being carried by a belt conveyor from a briqueting machine to the blast furnace. Above: Partly consumed fluedust briquets, showing how these hold together while undergoing melting in the furnace. Right: Machine for the briqueting of borings, turnings and millings from machine-shop waste. The finished blocks are discharged from the elliptical opening at the lower left of the vie

How scrap is compressed into large cakes where it could not profitably be handled loose 
$21,000,000$ pounds of bearing metals to carry the loads superposed upon the journals of the line's myriad car and locomotive wheels.

In machinery of all sorts hrass and bronze figure extensively, and these metals, when scrapped, are not infrequently associated or mixed with iron and steel. This is especially true in machine shops where the turnings from lathes, etc. dealing with various materials, are swept up together and dumped in common piles. Miscellaneous scrap of this character is of little or no value as it stands, because there should be no iron or steel in brass castings and no brass in ferrous ingots or castings. It is therefore highly desirable that the ferrous and the non-ferrous metals be segregated so that they may be made ready for remelting. This could not be done cheaply and rapidly on a

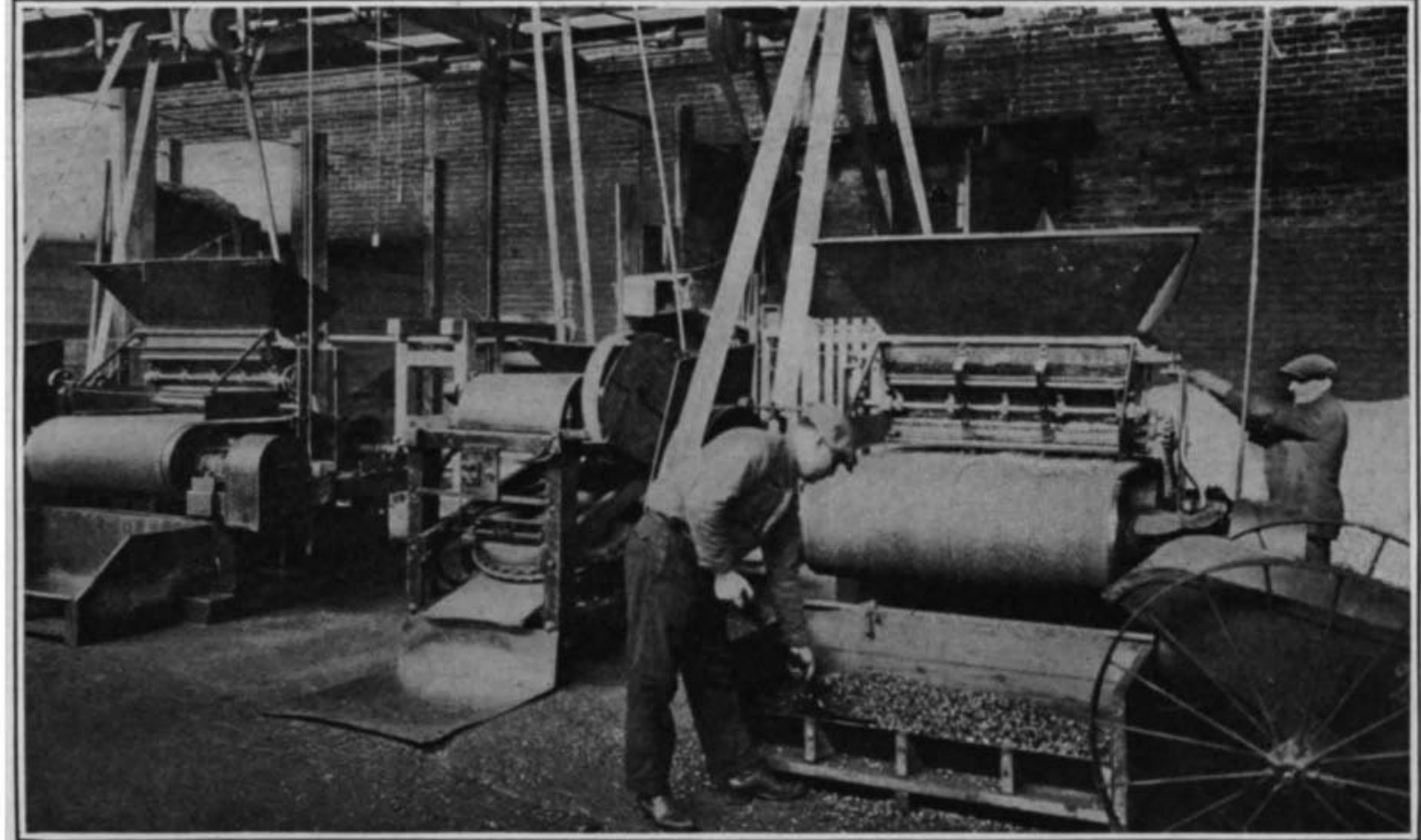

Two magnetic-pulley separators, on either side of a disk separator, also of magnetic type

can effect this penetration at any range.

The recent firing tests against the old battleship "Massachusetts," carried out by our Coast Defense Artillery, demonstrated the great effectiveness of high-angle fire; and this mount has been designed so that the gun can be fired at an elevation of 65 degrees. A 2,400-pound shell fired at such an elevation, and falling, as it would, almost vertically from a height of ser. eral miles, upon the deck of a ship would unquestionably penetrate to the vitals, eren were she a 43,000 -ton vessel with the great protective armor of our new "Indiana" class. It is a pretty safe guess that the effect of such a shot would be to cause the ship to fall out of line.

Tin Cans as Fuel

T might be left to the exwhether or not there is any

commercial scale but for the erolution of magnetic separators, which are obtaining steadily increasing recognition in our industrial life.

It has been said that a handful of iron will ruin a hundred pounds of babbitt metal; and iron in brass and copper alloys is likely to occasion grave trouble in working up the castings. This is owing to the manner in which iron forms into small nodules which absorb all of the carbon in the surrounding non-ferrous mass and become harder eren than the hardest of tool steel. If for example, the cutting tool strike any of these while machining a brass casting the instrument is apt to break, and, apart from the money loss in the damaged tool, the latter may injure the casting before the operator is aware of it. Plainly, much is to be gained by separating the antagonistic metals. Where borings and turnings are very oily it is needful to remove this coating before separation begins, inasmuch as the oil causes fine iron particles to stick to the other metals and thus to draw the latter along with the iron. This objectionable oil can be got rid of by rarious means. In general, in handling mixed metals, it is advisable to screen the chips through a half-inch mesh before feeding them to the separator. For the treatment of a combination of iron, steel, brass, copper, aluminum, or nickel scrap of this character, what is known as the disk-type of separator answers admirably.

In a machine of this sort the magnets consist of a large, stationary, primary magnet body and a scries of small, secondary induced magnets which are mounted upon a rotating disk. The primary magnet has heavy clouble coils and cores with pole pieces projecting down ward and conforming to the circle of the disk. The :econdary magnets, made of Swedish iron, are inductively energized by the primary magnet, but become demagnetized as they sreep beyond the neighborhood of the primary poles and of the primary poles and
when so weakened they drop any iron or magnetic maany iron or magnetic ma-
terial that they may have attracted. in this way the discharge falls into a conveyor and is transported to a near-by box or bin, while the non-magnetic substances are carried to another point of deposit.

For handling bulkier ma terials there has been de. vised a pulley-type of mag. netic separator. In apparatus of this kind the mag. netism is strong enough to exert itself at a given point through the conveyor belt that turns about it. In operation, as the mixture comes within the magnetic zone of the pulley, the magnetic bodies are attracted and carried around and beneath the magnet where they are released and free to fall into a receptacle, (Continued on page 415)
Our New Sixteen-Inch Barbette Coast-Defense Gun

I $\mathbf{N}$ oui issue of January 29th of this year we de 1 scrice and illustrated the new 16-inch, 170-ton, disappea $\therefore$ coast-defense gun, a type which is to be mounted in some of our most important fortifications. IVe now present a photograph of the same gun on the new barbette mount, which has been designed by Army Ordnance and built at the Watertown Arsenal. The mounting shown in this photograph is the first of its type to be built

The disappearing mount, it will be remembered, was designed to permit the loading and sighting of the gun to be done below the shelter of a massive sand-andconcrete parapet, with a view to giving protection to the gun and its mounting and the crew. After the gun is loaded, it is raised by its counterweight until the barrel is clear of the parapet, and on firing, the energy of recoil carries the gun back and down once more into the loading position. The barbette mount is simpler, inasmuch as the barrel of the gun is permanently exposed above the parapet. The mounting consists essentially of a carriage and a sleeve, the carriage rotating horizontally on a turntable and the sleeve rotating vertically on journals which form part of the carriage. The gun recoils within the sleeve, which carries the recoil cylinders for gradually absorbing the momentum and returning the gun again to the firing position.

The Army coast defense gun is a huge piece, 69 feet in length and weighing 170 tons. Its heaviest armor piercing projectile weighs 2,400 pounds and has a range of over 22 miles. The powder charge weighs 850 pounds, and the projectile has suffcient energy to penetrate any armor that ca be carried by a modern battleship; and it

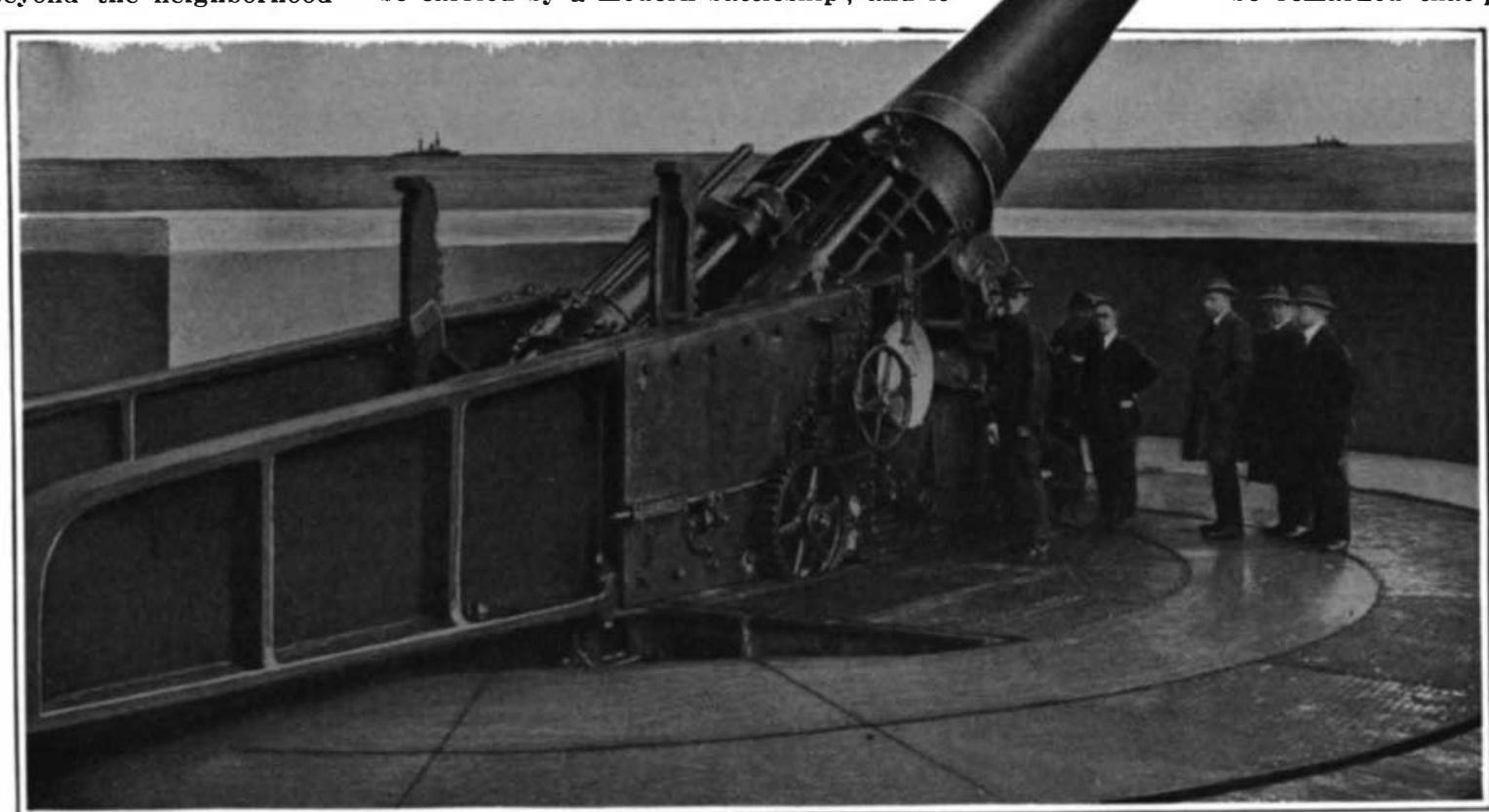

Our new 16-inch barbette, coast-defense gun, weighing 170 tons, which fires a 2400-pound shell to an extreme range of 22 miles material quantity of heat erolved in the burning of tin cans and if so just what their "fuel value" is. As an efficient and sanitary means for disposing of them there can be no question regarding their cremation.

That almost any quantity of tin cans can be conveniently disposed of by burning in an ordinary hot air or steam house-heating furnace cannot be generally known to householders at large or there would be less back yards, vacant lots and dumps cluttered up with this most unsightly and insanitary kind of refuse. As usually thrown out without the formality of rinsing, they are "smelly" and where they not infrequently lodge, they collect rain water and become most luxuriant breeding places for flies and mosquitoes. All this could be readily avoided by simply "firing" the cans into the furnace along with the other fuel. The burning of a tin can, as any other combustible, is a process of oxidation. Oxidation takes place slowly in the space above the fuel bed, because then if the fire is intelligently handled and there is a minimum of "air dilution" there will be no great amount of free oxygen. As the cans are allowed to sink deeper and deeper into the fuel bed, and, finally, into the underlying bed of ashes, they encounter more and more free oxygen which, at a comparatively high temperature, whils in their almost complete disappearance.

In order that they may be got rid of as quickly as possible it is best to put them into the furnace before firing on fresh coal. They should not be "poked" (neither should burning coal for that matter, except in very rare incidents), but left alone to sink gradually down to, and finally through, the grates, in which there will be nothing left of them but a few scattered fragments of brittle oxide. It may be remarked that practically all other refuse from the house can be disposed of in the same way.

To the city dweller this information may be of minor interest although it does not require a very vivid imagination or otherwise active mind to show what an improvement there would be in the outskirts of city infested with "dumps" if all combustible matter were disposed of in this way. The refuse from the usual dwelling house would be one product, and one product only-a mixture of fine ashes and clinkers, the former of which in the case of the rural and suburban owner can be readily separated out by dumping on an inclined screen for use in lightening the soil of the garden, and the latter, constituting about 50 per cent by volume, can be disposed of in the usual was or used in making concrete. 


\section{Putting Waste Metals to Work}

(Continued from page 405)
while the non-magnetic substances are swept by momentum off of the belt when it begins its downward course. Disk separators are built capable of treating from 300 to 1,200 pounds of material in the course of an hour, and the magneticpulley pattern of separator, according to size, is able to take care, in the same interval, of from 550 pounds up to nearly 40 tons of waste. Apart from doing what is quite impracticable by manual labor these separators recover values that otherwise would probably be lost. Magnetic pulley separators are extensively employed now in withdrawing iron and steel from blast-furnace slag, when crushed, and from the sand of foundries. Indeed, magnetic separators are reclaiming ferrous metals from ashes, grindings and sweepings, and helping to add largely to our stores of these secondary metals. So far, so good, but separation, in itself, does not suffice to insure the fullest reuse of the salvaged scrap.

Light, loose turnings, borings, etc., when remelted in that form, entail serious losses by excessive oxidation in the furnace These can be minimized by compacting or briqueting the material in advance. Machines are built which effect this by subjecting the bulky scrap to enormous pressure, and the result is a dense mass which will undergo melting with nearly as little loss as a like weight of solid metal. This may be done either at the source of the scrap or at the nearest plant that specializes in the briqueting of such material. From there it is returned in the form of so-called ingots or briquets. These can be forked, dumped, and handled without appreciable loss by abrasion; they facilitate economy in the use of crucibles because their shape and density permit a maximum weight of charge; and they promote greater output of recast metal in less time and at a lower cost for fuel. One establishment has a briqueting equipment which turns out from 16 to 20 briquets of steel turnings per minute and these run from 12 to 20 pounds each. The light steel for these briquets is bought at the market price for such scrap and, after compacting, is sold at a premium above the market price for so-called heavy-melting steel.

That the Government set an example in economy is evidenced by what was done at the U. S. Naval Gun Factory where, during three years' work, it was found that manganese bronze, previously supposed to be an exacting composition, could be made without resorting to highgrade rirgin metals. The alloy was produced in a reverberatory furnace from materials of low grade, such as yellow brass, machine-shop turnings, zinc dross from galvanizing pots, aluminum turnings, old zinc scrap, foundry-floor scrap and skimmings, and scrap copper. Simihearth steel could be made from cheap hearth steel could be made from cheap
unsalable scrap, and that a considerable unsalable scrap, and that a considerable
saving could thus be achieved over the saving could thus be achieved over the ordinary practice of utilizing practically all heavy and high-priced melting stock.

The use of lead batteries has expanded greatly through the development of the automotive industry and a large part of our secondary lead is obtained from old batteries. In 1919 the secondary lead recovered from various sources amounted to 122,100 tons. Considerable impure and low-grade lead scrap is now manufactured into toss here which previously came from abroad. Two years back the secondary tin salvaged was equal to about 42 per cent of the tin imported; it totaled per cent of the tin imported; it totaled Some of this was got from clean tin-plate Some of this was got from clean tin-plate
scrap and about 400 tons was recovered from scrap tin, clippings, old tin pipe, tin foil, and collapsible tubes. Nearly all clean tin scrap is detinned by one of three processes-the electrolrtic alkali, the chlorine, or the alkali saltpeter. By the (Continued on page 417)

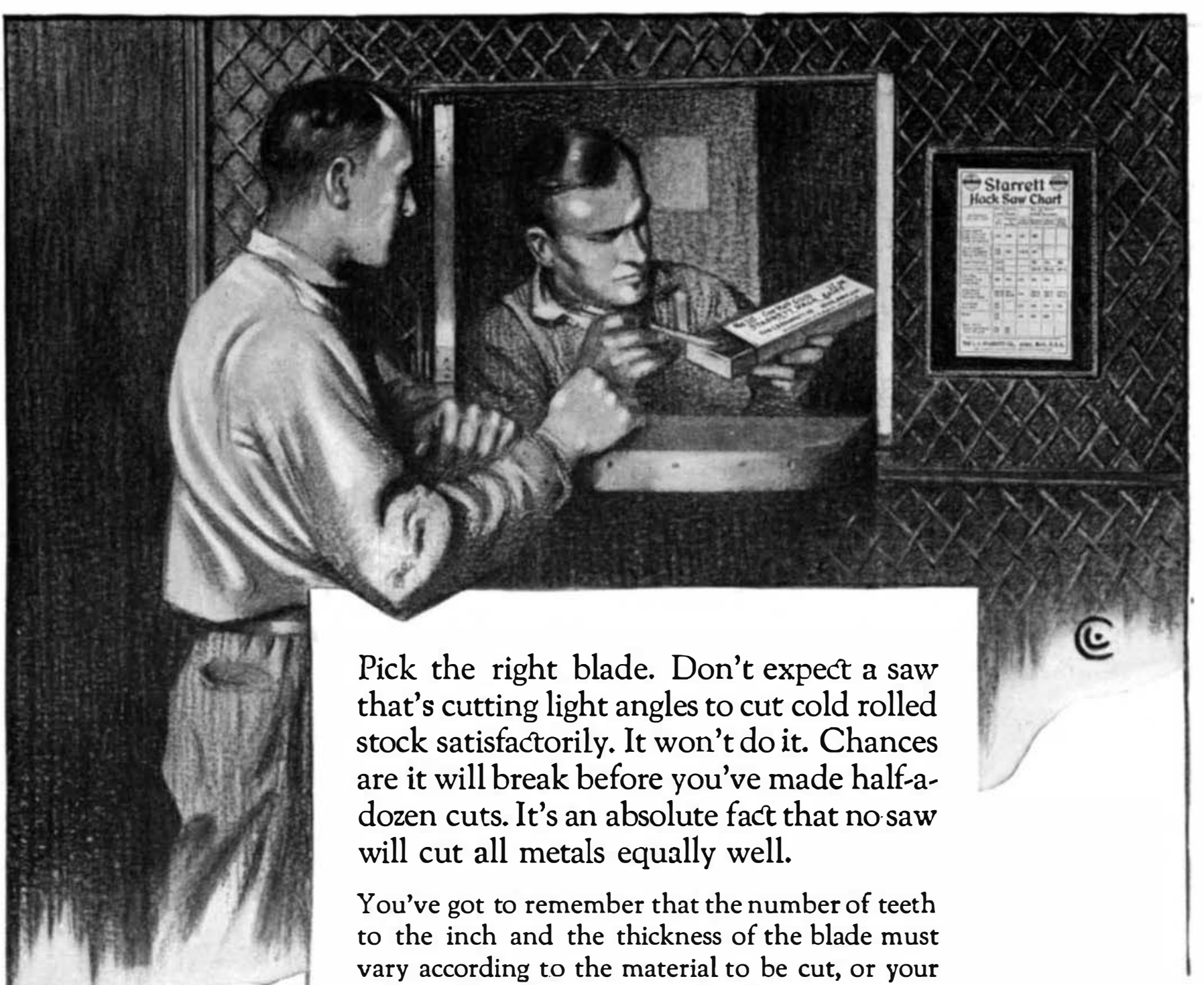
work will cost more than it should.

Look at your chart, choose the proper saw and flood the job with compound. Increase the pressure as the work progresses and you won't lose time or temper because the saw's not right.

If you haven't the Starrett Hacksaw Chart we will be glad to mail it to you. Free.

$$
\text { Send for Catalog Na. } 22 \text { "B" }
$$

THE L. S. STARRETT COMPANY
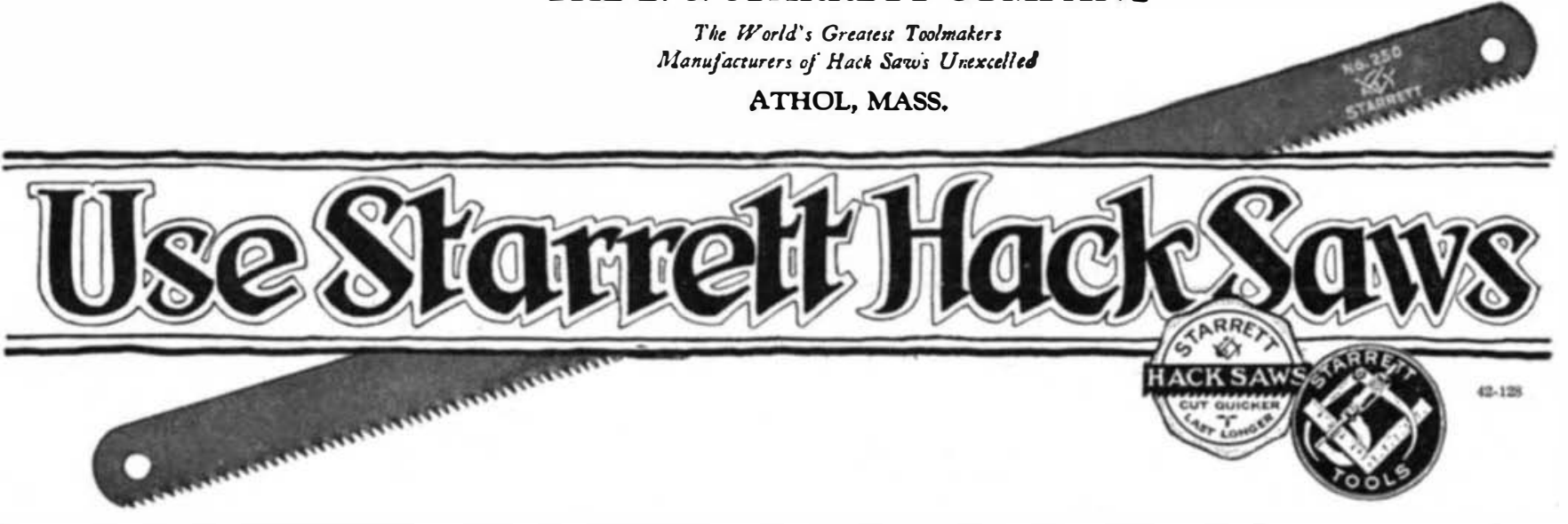

The Effect of Weight or Pressure $\mid$ mines the rate of cutting and the en- $\mid$ a pressure will allow the saw to slide The demonstrated advantage that durance of the blade. The proper and wear without doing effective cutThe demonstrated adve long life in hours, has resulted through the establishment $\begin{aligned} & \text { weight to be applied on starting the ting. This may show long life in hours, } \\ & \text { cut, and when and how much it should but also requires long periods per cut, }\end{aligned}$ of specific cutting speeds and feeds as cut, and when and how much it should but also requires long periods per cut, most economical in the case of the be increased, varies with different and results in an ultimate low efflathe tool, points to the necessity of makes of saws, and in the absence of ciency. On the other hand, excessive likecommendation by their makers can be pressure is unnecessarily destructive. conditions for efficient Hack Saw work, estimated only by trial and by compar- The saw may cut much faster while it as regards speed, pressure and lubri- ison of results. $\quad$ lasts, but it doesn't last long enough to cation for each type of saw and class justify the practice. Between these exof material.

The effect of pressure on the life of tremes lies the happy mean which repthe saw and how it affects cutting costs resents the acme of Hack Saw economy.

The most vital variable under ready is very clearly shown in the succeeding - From Hack Saws and Their Use, control is the pressure upon the saw, - tables and curves. From all of these, published by The L. S. Starrett Co., which, other things being equal, deter- $\mid$ it will be at once evident that too light $\mid$ Athol, Mass., for free distribution. 
Putting Waste Metals to Work (Continued from page 415) first method the tin is reclaimed in the form of a spongy granulated precipitate, which can be remelted into pig tin; by the second, tetrachloride of tin is recovered for use in the reighting and the dyeing of silk; and by the third procedure the tin is secured as an oxide which is employed as a coloring agent in the enamel industry or melted into pig tin by means of a rererberatory furnace.

Aluminum chips from castings produced in the making of automobiles have become a large source of secondary aluminum. By the old treatment the loss in remelting such chips was sometimes as high as 40 per cent, but gorernment experiments revealed awhile back that it was quite practicable to lower this loss to as little as 10 per cent. The secondary aluminum, in the shape of pig aluminum or in alloys, totaled a matter of 18,691 short tons in 1919, and ras valued at $\$ 12,014,600$. Various products are made by smelters and refiners from scrap aluminum. During the same year we obtained 2,447 short tons of secondar nickel worth $\$ 1,829,400$. Of the resultan refined nickel, about 60 per cent is used in nickel steel, 30 per cent in white-meta alloys, 5 per cent in anodes for plating, and 5 per cent for miscellaneous purposes, including the manufacture of salts and other chemical compounds. As has been rell said, "By depriving the market of ans useful scrap metal the price of rirgin metal is driven up proportionately."

Finally, in sketching the potential savings through the recovers of secondar metals, let it be said that blast-furnace flue dust, which is so often neglected, has an iron content of more than 40 per cent By briqueting this dust it can be fed back to the furnace and much of the valuable iron in it can be melted and cast into marketable pigs. The recent perfecting of machinery for briqueting thi material opens up channels to tremendou economies. Our large industrial enterprises are profiting by the lessons learne during the late confict, but the thing needful is to impress upon their smaller brethren that they, too, ought to adopt the same practices so that the nation as a whole may be the better fitted to cope with the foreign producer.

The Truth About the Dye Industry (Continued from page 408)

for the production of essential pharma ceuticals. Some of the most necessar drugs for the maintenance of public health are produced from coal-tar products. I will mention only such things as salvarsan, aspirin, novocain and phenacetin.

Prior to 1914 we were entirely dependent upon Germany for these products ; toray. physicians and dentists will tell you that they are difficult to obtain, and are very expensire. The have not zet been produced adequately by the American dyestuff manufacturer, but given a fair field this is the next step of development which, already in preparation, is bound to come. Is it not advisable that an industry which can yield such substances for the relief and benefit of the human race should be maintained?

Again, we are reaching a point where in many sections of our country, the soil has become exhausted and requires replenishment with those necessary chemical ingredients which enable it to yield its full percentage of crops. These chemicals again come from the collateral chemical lines intimately connected with the coaltar chemical industry, such as the products of nitrogen from the air, which make possible the necessary nitrates and the manufacture of ammonia, as well as other chemical factors which are indispensable to the proper preservation of land values.

Finally, the preservation of the coaltar chemical industry is indissolubly as- sociated with the national welfare, in that it is from this industry that the high exlosives and poison gases are obtained which have made modern warfare what realized it to be in 1917-1918.

The country which has a well-estabished coal-tar chemical industry, is the country which is ready to meet an aggressire attack almost at a moment's notice. The same plants which produce coaltar colors can be changed and diverted into the manufacture of poison gases and high explosires with the least possible margin of delar - to use a slight literary exaggeration, almost over-night.

For instance, there is a black dye, sulfur black, very extensively used for dyeing our black cotton stockings. In its finished state, it is simply a harmless, grasish-black powder. If the process of its manufacture horrever had been stopped before the last step was completed, and had been switched off in another direction, we should have produced picric acid, one of the most powerful explosives known.

Again, a certain brilliant yellow dye, made from coal tar, and in universal use for obtaining delicate golden tints, if also stopped before the completion of the final step, produces one of the most deadly forms of poison gas, a gas which renders modern rifie fire and the machine gun ineffective and useless to the same degree as the high-powered bullet threw into the discard the shoulder-to-shoulder formations and solid squares of the days of Waterloo.

There is a story, which may be apocryphal, that prior to 1914 one of the largest German dyestuff manufacturers was making, under instructions from Berlin, large quantities of di-nitrotoluol. There was no particular market for this product, and they simply continued its manufacture, piling up huge quantities without any apparent outlet for it. When the war broke suddenly upon the world in 1914, instruction came from Berlin to add one part of nitric acid to this di-nitrotoluol and it was immediately converted into tri-nitrotoluol一TNT.

With this TNT Germany battered down the walls of Liege and Antwerp and blasted her way through Belgium and northern France, while the Allies were still under the delusion that they could hold back her gray hordes by peppering them with shrapnel.

Some weeks ago a squadron of airplanes flew over the lower part of New York. They were a beautiful sight, and the surging crowds filling the streets at the noon hour watched them with admiration and interest. In their passage over the business district, they dropped smoke bombs and marked the places where they struck. The layman cannot easily imagine what bombs filled with but the expert knows. Theoretically, these planes destroyed the whole lower part of New York and its dense day-time population in fifteen minutes. And this destruction would have been caused by products obtained from the coal-tar hemical industry.

Do we want to see this country placed a position where such a thing as this might easily happen; where from the decks of a line of mother ships anchored twenty miles off shore, such a squadron might have been sent to cause this destruction without any possibility of defense? The world is sick of war, but is there anyone who is so optimistic as to believe that war has been finally abolished? As long as human ambition leads individuals to seek the glory that comes from triumphant war, as long as the surging yellow and brown hordes of orerpopulated countries are seeking outlet for their millions who are starving to death on their own resources; as long as the industry and commerce of a nation develop beyond the point where its products can be absorbed by the home mar(Continued on page 419)

\section{$\underline{\text { Now Ready }}$}

\section{Einstein's Theories}

of Relativity and Gravitation

360 pages, $12 \mathrm{mo}$.

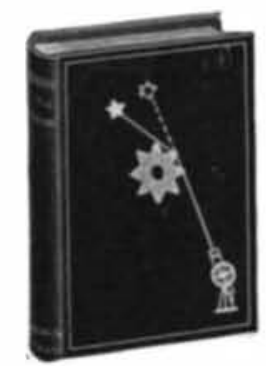

$\$ 2$ net. By mail, $\$ 2.15$

At all booksellers.

A book that everyone can understand-a book that no "well-informed" person can afford to miss.

It contains the best material submitted by 300 authors in the Scientific AMERICAN competition for the Eugene Higgins prize of $\$ 5,000$. It gives you the clearest thoughts of the greatest authorities-"Einstein at a glance."

Edited by J. MALCOLM BIRD

\section{Scientific American Publishing Company}

233 Broadway, New York

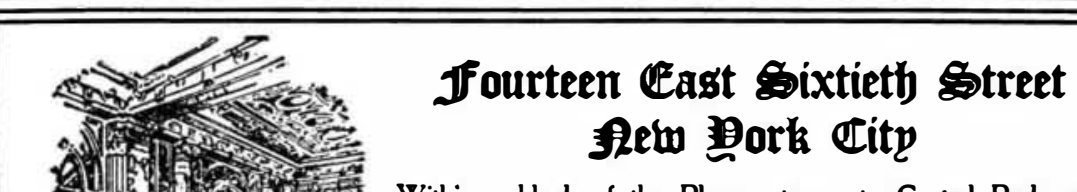

Within a block of the Plaza entrance to Central Park, with easy access to the theatres, clubs and shopping centers.

An exclusive place for either temporary or prolonged abode, offering every appeal to the most exacting taste, sumptuous in urmishings, unsurpassed in cuisine, with the comfort inspiring atmosphere of the modem well-appointed home.

Plans of the rooms and prices gladly submitted on request.

Eager \& Tabcock

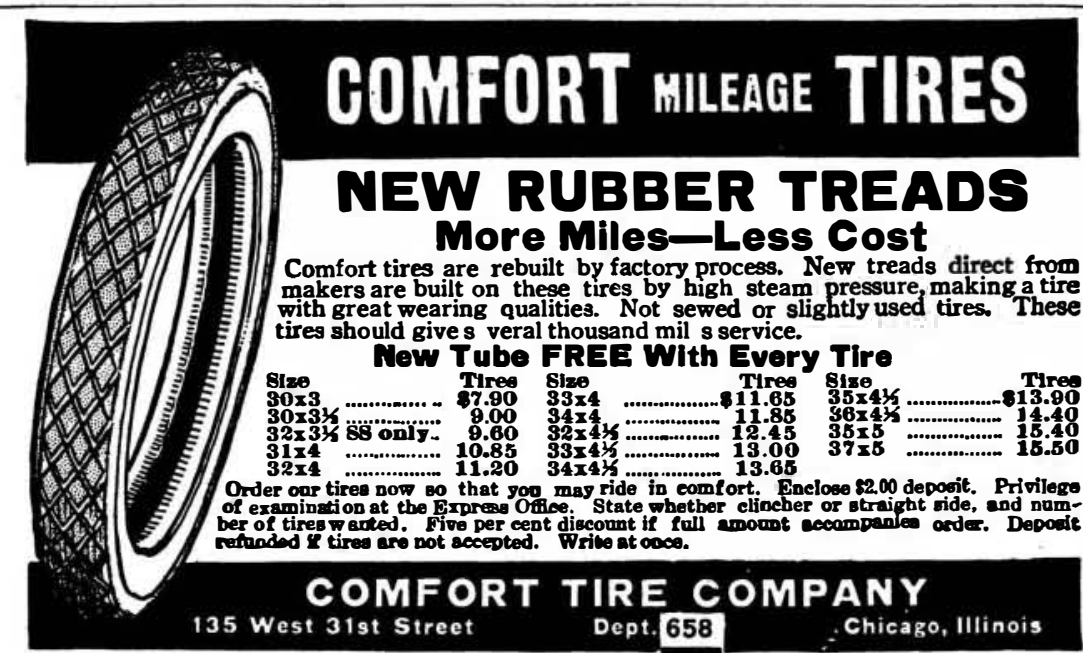

